\title{
$\boldsymbol{\nabla}$ Artikkeli
}

\section{Medioituminen: iskusana, analyyttinen työkalu vai uusi paradigma?}

\begin{abstract}
Medioitumisen käsite on noussut näkyvästi esille viestinnän ja median tutkimuksessa viime vuosina. Muutamat tutkijat ovat pyrkineet jopa nostamaan sen mediatutkimuksen keskeiseksi käsitteeksi ja tulkintahorisontiksi. Käsite on kuitenkin jäänyt useista määrittely-yrityksistä huolimatta suhteellisen ambivalentiksi ja monitulkintaiseksi. Tässä artikkelissa jäsennämme tätä hajanaista kenttää erottamalla kaksi teoreettista tulkintaa medioitumisesta: vahvan ja heikon version. Vahvan tulkinnan mukaan "medialogiikka" määrittää yhä enemmän eri yhteiskunnan instituutioiden ja ryhmien toimintaa. Heikko versio puolestaan kyseenalaistaa yhden medialogiikan olemassaolon, vaikka korostaakin samalla median kasvavaa merkitystä yhteiskunnassa. Se näkee medioitumisen yhtenä keskeisenä yhteiskunnallisena "metaprosessina". Arvioimme kriittisesti sekä vahvan että heikon version lähtöoletuksia ja johtopäätöksiä median roolista yhteiskunnassa. Lisäksi pohdimme medioitumisteorian merkitystä mediatutkimuksen identiteetille, mikä on keskeistä pyrittäessä ymmärtämään medioitumista koskevan keskustelun viimeaikaista suosiota.
\end{abstract}

AVAINSANAT: medioituminen, medialogiikka, mediatutkimus, teoria, kritiikki, tieteenalaidentiteetti, tutkimusrahoitus edioitumisen (mediatization) käsite on noussut esiin viime vuosina lukuisissa konferensseissa, seminaareissa, kirjoissa, artikkeleissa ja mediaa koskevissa tutkimuksissa. Vaikka käsite esiintyi eri muodoissa jo 1980- ja 1990-luvuilla (esim. Asp 1986; Thompson 1995; Somerville 1997; Fornäs 1998; Mazzoleni \& Schultz 1999), 2000-luvulla se on nimetty "avainkäsitteeksi" (Lundby 2009), jonka avulla mediatutkijat yrittävät hahmottaa median muuttuvaa roolia ja merkitystä yhteiskunnassa ja kulttuurissa.

Käsite on ollut erityisen suosittu Pohjoismaissa, Saksassa ja Keski-Euroopassa. Myös englanninkielisellä alueella tämä hiukan "kömpelö uudissana" (Livingstone 2009, 6) on herättänyt mielenkiintoa, joskin muutamat tutkijat ovat käyttäneet sen sijaan termiä mediavälitteisyys (mediation) mieluummin kuin medioituminen (esim. Silverstone 2005). Yhtä kaikki, medioituminen on noussut esille alan tutkimuskirjallisuudessa yhä laajemmin. Brittiläinen mediatutkija Nick Couldry (2008) suhtautui aiemmin skeptisesti medioitumisen käsitteeseen ja käytti mieluummin termiä mediavälitteisyys (mediation). 
Myöhemmin hän on kuitenkin todennut, että "kansainvälistyvällä tutkimuksen kentällä kielellistä käyttökelpoisuutta tulee arvioida globaalilla tasolla" ja "on selvästi hyödyllistä hyväksyä erottelukykyisempi termi eli medioituminen" (Couldry 2012, 134). Käsitteen suosion nousu näkyy selvästi myös alla olevassa taulukossa 1, joka esittää Google Scholaria käyttämällä saadut hakutulokset termille "mediatization".

Taulukko 1: Google Scholarin hakutulokset sanalle "mediatization"

\begin{tabular}{|l|l|l|}
\hline Vuodet & Otsikossa & Koko tekstissä \\
\hline $2000-2001$ & 6 & 201 \\
\hline $2010-2011$ & 80 & 1580 \\
\hline $2012-2013$ & 119 & 2440 \\
\hline
\end{tabular}

Termin mediatization lisäksi medioitumisesta on englannin kielessä käytetty monia erilaisia muotoja kuten "medialization" (Asp 1986) tai "mediazation" (Thompson 1995). Suomessa, ainakin keskustelupuheessa, tästä ilmiöstä on käytetty myös ilmauksia medialisaatio, mediatisaatio, medialisoituminen tai mediatisoituminen. Tässä käytämme kuitenkin sanaa medioituminen termin mediatization suomennoksena. Tämä käännös on jo suhteellisen vakiintunut viestinnän ja mediatutkimuksen kirjallisuudessa. Ensimmäisen kerran "medioituminen" esiintyi mediatization-termin suomennoksena tiettävästi Johan Fornäsin (1998) Kulttuuriteorian käännöksessä. Myöhemmin termiä ovat käyttäneet esim. Herkman (2001), Lehtonen (2002), Väliverronen (2002), Kunelius, Noppari ja Reunanen (2009) ja Kantola (2011). Toisaalta Sumiala (2010, 112) on ehdottanut mediatization-käsitteen suomennokseksi "medialisaatio" ja vastaavasti mediation-termin suomennokseksi "medioituminen". Koska medioituminen on käännöksenä jo jossain määrin vakiintunut ja myös kielellisesti sujuvampi, käytämme tässä sitä mediatization-termin käännöksenä. Tosin tämä sujuvuus on omiaan häivyttämään erään mediatization-termiin liittyvän ongelman: medioituminen (tai medialisaatio) on globalisaation käsitteen tavoin hankala, koska tällaista kielellistä substantivointia käytettäessä usein annetaan ymmärtää, että medioituminen tai medialisaatio olisi ikään kuin toimiva subjekti, joka saa aikaan erilaisia seurauksia.

Keskeinen kysymys medioitumisen käsitteessä on se, onko kyseessä nimenomaan analyyttinen kategoria vai pikemminkin kuvaileva termi (Väliverronen 2001). Viimeaikaisessa kirjallisuudessa monet tutkijat ovat pyrkineet hahmottamaan medioitumista nimenomaan analyyttisena kategoriana (esim. Schulz 2004; Krotz 2007; Krotz 2009; Hjarvard 2008). Useista määrittely-yrityksistä huolimatta medioituminen on jäänyt kuitenkin suhteellisen ambivalentiksi ja monitulkintaiseksi.

Hankaluudet medioitumisen määrittelyssä liittyvät olennaisesti itse median käsitteen määrittelyn pulmiin. Media juontuu latinan medium-sanasta. Englannin kielessä käytetään myös yleisesti yksikkömuotoa medium sekä monikkoa media, jolla viitataan viestintävälineiden kokonaisuuteen (alun perin lähinnä lehdistön, elokuvan, radion ja television kaltaisiin joukkoviestimiin mainonnan välineinä, ks. Williams 1983, 203). Koska medium ei ole juurtunut suomen kieleen, on meillä tullut tavaksi puhua yksi- 
kössä mediasta ja monikoissa medioista. Lisäksi mediasta puhutaan usein kuin se olisi itsenäinen, oma alueensa tai instituutionsa ("neljäs valtiomahti"). Ennen internetin yleistymistä mediamaisema piirtyikin suhteellisen selkeästi: televisio, radio ja lehdistö muodostivat joukkoviestinnän, median ytimen. Nykyisin viestintäkäytännöt ovat internetin ja muiden teknisesti välittyneiden keskinäis- ja ryhmäviestintämuotojen myötä moninaistuneet - samalla kun niitä koskeva tutkimus on laajentunut ja tämä on johtanut joukkoviestinnän käsitteen syrjäytymiseen väljemmän "median" käsitteen tieltä. Viestinnän muotojen moninaistuminen on tehnyt median käsitteen täsmällisen määrittelyn hankalaksi (ks. esim. Seppänen \& Väliverronen 2012, 14-15, 22-24). Lisähankaluutena on, että medialla voidaan oikeastaan viitata mihin tahansa mikä välittää merkityksiä (Koivisto \& Thomas 2010, 35-36). Valitettavasti medioitumisen puolestapuhujat eivät ole paljoakaan paneutuneet median käsitteen merkityksiin ja niihin liittyviin ongelmiin. Käsitteen analyyttisen pohdinnan sijaan he näyttävät luottavan lukijoidensa kykyyn luoda mielessään median käsitteelle näennäistä koherenssia aina tilanteeseen sopivien esimerkkien avulla.

Jäsennämme tässä artikkelissa medioitumiskeskustelun hajanaista kenttää erottamalla kaksi medioitumisen teoreettista tulkintaa, vahvan ja heikon version. Vahvan tulkinnan mukaan "medialogiikka" määrittää yhä enemmän eri yhteiskunnan instituutioiden ja ryhmien toimintaa. Heikko versio puolestaan kyseenalaistaa yhden medialogiikan olemassaolon, vaikka korostaakin samalla median kasvavaa merkitystä yhteiskunnassa. Se näkee meditoitumisen yhtenä keskeisenä "metaprosessina" yhteiskunnassa. Arvioimme kriittisesti sekä vahvan että heikon version lähtöoletuksia ja johtopäätöksiä median roolista yhteiskunnassa. Millaisen käsitteellisen maaston medioitumisteoria tarjoaa viestinnän ja median tutkijoille? Lisäksi pohdimme medioitumisteorian merkitystä mediatutkimuksen identiteetille. Tarjoaako medioituminen peräti uuden paradigman, jonka avulla mediatutkimus voi saavuttaa itsenäisemmän roolin suhteessa muihin yhteiskunta- ja kulttuuritieteisiin?

\section{Politiikan medioitumisesta yhteiskunnan ja kulttuurin medioitumiseen}

Medioitumisen käsitteen ala on laajentunut merkittävästi viimeisten 10-15 vuoden aikana. Alkuvaiheessa sillä viitattiin yleensä lähinnä tiettyihin alueisiin tai prosesseihin, kuten politiikan medioitumiseen (Mazzoleni \& Schulz 1999) tai joskus myös tieteen medioitumiseen (esim. Väliverronen 2001; 2002). Edelleenkin termin käyttö lienee yleisintä juuri puhuttaessa politiikan ja poliittisen viestinnän muutoksista. Toisinaan esitetyn argumentin mukaan media ei ole vain ottanut suurempaa roolia julkisessa mielipiteenmuodostuksessa, vaan mediasta on tullut myös politiikan keskeisin instituutio.

Jo 1970-luvun lopulla Altheide ja Snow väittivät, että "poliittista elämää muotoillaan uudelleen niin, että se soveltuu valtamedian vaatimuksiin" $(1979,136)$ ja tämän seurauksena siitä on tulossa "mediatuotannon jatke" (emt., 146). Ruotsalainen politii- 
kan ja median tutkija Kent Asp huomautti 1980-luvulla, että "politiikan toimijat joutuvat yhä enemmän mukautumaan niihin vaatimuksiin, joita media asettaa politiikan tapahtumien raportoinnille. Tätä kehitystä voi kutsua 'politiikan medioitumiseksi'" (Asp 1986, 380). Esimerkkinä politiikan medioitumisesta Asp mainitsi henkilöitymisen, yksinkertaistamisen ja konfliktien kärjistämisen. Median vaatimuksiin mukautuvista tulee näyttelijöitä politiikan näyttämöllä. Asp ei kuitenkaan kehitellyt ajatusta medioitumisesta pidemmälle ja epäilemättä hän myös liioitteli politiikan muutoksia: teatterin elementit kun ovat olleet osa politiikkaa paljon aiemminkin.

Mazzolenin ja Schulzin (1999, 250) mukaan "medioituneessa politiikassa politiikka on menettänyt autonomiansa ja sen keskeiset toiminnat ovat muuttuneet mediasta riippuvaisiksi". Verrattuna neutraaliin mediavälitteisyyteen medioituminen viittaa siis siihen, miten mediasta on tullut keskeinen ellei peräti kaikkein keskeisin politiikan instituutio. Todellisuudessa median ja politiikan suhteet lienevät kuitenkin monimutkaisemmat, mistä Mazzoleni ja Schultz (emt., 258-26o) jo muistuttivat. Siinä missä keskustelu politiikan medioitumisesta on kohdistunut usein median lisääntyvään autonomiaan ja valtaan (Hjarvard 2008), esimerkiksi Kunelius, Noppari ja Reunanen (2009; myös Reunanen, Kunelius \& Noppari 2010) ovat luonnostelleet monimuotoisemman lähestymistavan medioitumisen empiiriseen tutkimukseen analysoimalla tarkemmin median ja politiikan toimijoiden keskinäistä vuorovaikutusta. Heidän mukaansa politiikan medioitumista tutkiessa on otettava huomioon se erityinen poliittinen kulttuuri, jossa vuorovaikutus päätöksentekijöiden ja median välillä kulloinkin tapahtuu.

Jotkut tutkijat ovat laajentaneet medioitumisen käsitteen kuvaamaan yleisempiä yhteiskunnallisia muutosprosesseja. Medioitumisesta onkin tullut eräänlainen sateenvarjokäsite, jonka avulla pyritään selittämään laajasti yhteiskunnan ja kulttuurin muutoksia: "medioitumisen käsite pyrkii tavoittamaan yhtäältä median muutoksen ja toisaalta sosiaalisen ja kulttuurisen muutoksen välisen pitkäaikaisen vuorovaikutuksen" (Hepp, Hjarvard \& Lundby 2010, 223). Kaikki medioitumisen teoreetikot eivät oleta, että media muodostaa yhteiskunnan ja kulttuurin hallitsevan keskuksen (ks. esim. Krotz 2007). He ovat kuitenkin yhtä mieltä siitä, että mediasta on tullut entistä tärkeämpi tai jopa ratkaisevan tärkeä tekijä kaikilla yhteiskunnan ja kulttuurin alueilla (esim. Krotz 2009, 24; Hjarvard 2008, 105; Hepp 2009, 141). Nämä tutkijat väittävät, että medioituminen tulisi ymmärtää "metaprosessiksi" (Krotz 2007) joka on "samantasoinen kuin modernisaation, yksilöllistymisen ja globalisaation kaltaiset keskeiset yhteiskunnalliset muutosprosessit" (Strömbäck \& Esser 2009, 208). Medioitumisen puolestapuhujat siis väittävät, että medialla on keskeinen rooli yhteiskunnallisten muutosten analyysissa, mikä yhteiskuntatieteilijöiden tulisi ottaa paremmin huomioon. Medioitumisella on jopa viitattu "uuteen yhteiskunnalliseen tilanteeseen", jossa "media yhä enemmän läpäisee koko kulttuurin ja yhteiskunnan" niin, että "kaikki medioituu" (Hepp, Hjarvard \& Lundby 2010, 224).

Kuvailevalla tasolla medioitumisen ajatus on helppo hyväksyä. Erilaiset teknisesti välittyneet viestinnän muodot ovat levittäytyneet osaksi kehittyneitä yhteiskuntia. Internet ja erilaiset sosiaaliset mediat ovat tehneet viestinnän sisältöjen tuotannosta 
ja levityksestä suhteellisen helppoa. Tekniset mahdollisuudet viestintään ja vuorovaikutukseen ovat laajentuneet merkittävästi. Media on yhä useammin mobiilia ja kaikkialla läsnä olevaa: eri kommunikaatiovälineistä on tullut elimellinen osa yhä useampien ihmisten arkea. Vaikka medioiden läsnäolo ihmisten ja instituutioiden arjessa on itsestäänselvyys, medioitumisen käsitteen analyyttinen ja teoreettinen määrittely vaatisi vielä paljon tarkennuksia. Vaikka medioitumisesta on julkaistu viime aikoina paljon kirjallisuutta, edes sen kannattajilla ei ole yhtenäistä näkemystä käsitteestä.

Jotta medioituminen ei jäisi pelkästään muodikkaaksi iskusanaksi, useat tutkijat ovat pyrkineet antamaan käsitteelle tarkemman analyyttisen statuksen ja sisällön. Näkemykset median autonomiasta ja vallasta yhteiskunnassa kuitenkin vaihtelevat suuresti. Joidenkin tutkijoiden mukaan median valta suhteessa muihin instituutioihin on kasvanut merkittävästi, jopa niin että ne ovat menettäneet autonomiansa ja alistuneet "medialogiikalle" (Hjarvard 2008). Näissä tulkinnoissa media ymmärretään itsenäisenä instituutiona. Toiset ovat taas sitä mieltä, että itse medioitumisen prosessia välittävät olennaisesti muut yhteiskunnalliset prosessit kuten yksilöllistyminen, globalisaatio ja kaupallistuminen (Krotz 2007; 2009). Lisäksi medioitumisen puolestapuhujat ovat pyrkineet määrittelemään medioitumisessa eri tasoja ja ulottuvuuksia (Hepp 2009, 142-144; Schultz 2004). Kaikille näille pyrkimyksille on yhteistä tavoite operationalisoida käsite konkreettisen tutkimuksen tarpeisiin. Medioitumisen puolestapuhujat eivät siis enää käytä sitä pelkästään kuvailevana käsitteenä, vaan ovat pyrkineet kehittämään siitä teoreettisen tutkimusohjelman, jonka avulla tutkijat voivat organisoida ja raportoida havaintoja median roolista yhteiskunnan ja kulttuurin muutoksissa.

\section{"Medialogiikka": vahva versio}

Vahva tulkinta medioitumisesta lähtee siitä, että nykyisin "media läpäisee koko yhteiskunnan" (Hjarvard 2008, 105). Tästä seuraa, että mediaa ei voi enää käsitteellistää "yhteiskunnan ulkopuolisena toimijana, joka vaikuttaa eri tavoin kulttuuriin ja yksilöihin" (Hepp, Hjarvard \& Lundby 2010, 223). Tämä luo "uuden yhteiskunnallisen tilanteen (emt., 224), mitä Hjarvard (2008) kutsuu "yhteiskunnan medioitumiseksi". Luonnehtiessaan median keskeistä roolia yhteiskunnassa Hjarvard nojautuu medialogiikan käsitteeseen, joka on peräisin Altheidelta ja Snow'Ita. Altheide ja Snow ovat antaneet medialogiikalle määritelmän, joka tosin Strömbäckin ja Dimitrovan $(2011,33)$ mukaan jää hiukan "hämäräksi":

medialogiikka rakentuu tietyistä viestinnän muodoista; kyse on prossesista, jossa media esittää ja välittää informaatiota. Tämä muoto koostuu useista medioista ja niiden käyttämistä formaateista. Formaatti muodostuu mm. materiaalin organisoinnin tavasta, esitystyylistä, tavasta fokusoida tiettyihin ihmisten käyttäytymisen piirteisiin ja viestinnän kieliopista. Formaatti muodostaa kehyksen tai näkökulman, josta käsin puheena olevia ilmiöitä esitetään ja tulkitaan. (Altheide Q Snow 1979, 10) 
Äskettäin Altheide $(2013,225)$ on todennut, että uudet informaatioteknologiat ovat "laajentaneet ja monimutkaistaneet uusien mediavälitteisten muotojen kehittymistä". Silti hänen mielestään "perustava käsitteellinen logiikka" on yhä olemassa ja sitä voi kutsua edelleen medialogiikaksi. Siksi Altheiden mielestä nykyisin tarvitaan vain tiettyjä "käsitteellisiä tarkennuksia kattavamman medialogiikan teorian" kehittämiseksi (emt., 223, 225).

Siinä missä Altheide kiinnittää huomiota formaatteihin, jotka ohjaavat symbolista tuotantoa, Hjarvard korostaa "median institutionaalista ja teknologista toimintatapaa" (Hjarvard, 2008, 113) ja sitä, miten medialla on yhä enemmän vaikutusvaltaa muihin instituutioihin. Tämän seurauksena muut instituutiot kuten politiikka "ovat tulleet entistä riippuvaisemmiksi mediasta ja alkaneet mukautua median logiikkaan" (emt.). Schultz $(2004,89)$ käyttää samaa argumenttia ja toteaa, että poliitikot ja puolueet joutuvat "mukautumaan television 'medialogiikkaan', toisin sanoen sen tuotantorutiineihin ja esitysformaatteihin". Strömbäck ja Esser (2009, 206-207) taas korostavat, että poliittiset väittelyt vastaavat yhä enemmän "median tarpeita" eli sitä, mitä media pitää uutisarvoisena "eikä niinkään ehdokkaiden tai äänestäjien tarpeita". Ihmiset ovat alkaneet kokea politiikan median kautta ja seuraavat "median muovaamia debatteja". Televisioidut väittelyt John F. Kennedyn ja Richard Nixonin välillä 1960 tarjoavat tärkeän historiallisen viitepisteen tälle argumentille, joka on myöhemmin saanut lisää tukea sellaisten politiikkojen kuten Silvio Berlusconin ja Tony Blairin mediaesiintymisen analyyseista (ks. esim. Mazzoleni \& Schultz 1999, 247-248). Kaiken kaikkiaan, media ei enää pelkästään välitä politiikkaa, vaan politiikka on "yhä enemmän medioitunutta" (Strömbäck \& Esser, 207). Politiikka on vain yksi esimerkki medioitumisesta, sillä samankaltaisia trendejä löytyy urheilusta, uskonnosta, viihteestä, tieteestä, identiteettien rakentumisesta, kuluttamisesta jne. (Schultz 2004, 89; Lundby 2009, 7).

Vahvassa teoriassa medioituminen nähdään lineaarisena prosessina. Strömbäck ja Esser (2009, 216) esittävät, että mediasisältöjä ei enää ohjaa poliittinen logiikka vaan medialogiikka, joka on poliittisten toimijoiden kannalta pakottava. Niinpä ainakin kehittyneissä teollisuusmaissa "median vaikutusvalta" on kasvanut valtavasti (emt., 208). Schrott (2009, 47) väittää samoin, että "toimijoilla on paine antaa periksi medialogiikalle, sillä he näkevät medialla olevan kausaalista voimaa määritellä ja tulkita sosiaalista todellisuutta". Tämä väite johtaa toiseen väitteeseen, jonka mukaan medioista on aikaa myöten tullut itsenäisempiä ja riippumattomampia muihin instituutioihin nähden - ja samalla yhä voimakkaampia. Tässä yhteydessä mediat eivät viittaa erityisiin formaatteihin tai organisaatioihin vaan kokonaiseen "symbolien, merkkien, viestien, merkitysten ja arvojen tuotannon, lähettämisen, kierron ja levittämisen" järjestelmään (Strömbäck \& Esser 2009, 209).

Hjarvardin (2008) tulkinnan mukaan medialogiikan voimistuminen ja median autonomian lisääntyminen tulee ymmärrettäväksi sosiologisen modernisaatioanalyysin taustaa vasten. Hjarvardin perinteisen liberaalifunktionalistisen näkemyksen mukaan modernisaatio tarkoittaa lisääntyvää eriytymistä eli sellaisten instituutioiden kehittymistä, jotka ottavat kantaakseen toisistaan poikkeavia tehtäviä yhteiskunnan ja kulttuurin eri saroilla. Mitä mediaan tulee, varhaisen modernin yhteiskunnan kehitysvai- 
heessa sanoma- ja aikakauslehdet loivat perustan poliittiselle julkisuudelle samalla kun erilaiset viihteelliset mediat palvelivat kulttuurisia tarpeita. Kuitenkin "tässä yhteiskuntakehityksen vaiheessa mediat eivät vielä olleet muodostuneet itsenäisiksi instituutioiksi. Sen sijaan ne olivat pääasiassa välineitä toisten instituutioiden käsissä" (emt., 117) - millä Hjarvard viittaa erityisesti poliittisiin puolueisiin. Muun muassa julkisen yleisradiotoiminnan ja suurelle yleisölle suunnattujen sanomalehtien synnyn myötä tilanne alkoi Hjarvardin mukaan muuttua: medioista "tuli kulttuurisia instituutioita jotka vetosivat kaikkiin ja tarjosivat jotain jokaiselle" (emt., 118). Tätä kehitystä voimisti journalismin ammattimaistuminen, joka tarkoittaa - ainakin journalistien itseymmärryksessä - "kriittistä asennoitumista poliittisiin ja kaupallisiin intresseihin" (emt.). Myöhemmät kehityskulut, kuten julkisen palvelun mediayhtiöiden monopoliaseman purkautuminen ja mediakentän kaupallistuminen 1980-luvulta lähtien, edustavat Hjarvardille median itsenäistymistä. Hän näkee, että mediat ovat tulleet lähemmäksi vastaanottajiaan: "siinä missä mediat varhaisemmin olivat lähettäjien ohjaamia, toisin sanoen erityisten intressiryhmien ohjauksessa esimerkiksi puoluelehdistön kulta-aikana tai julkisen yleisradion toimilupaehtojen ohjaamia, nykyiset mediainstituutiot ovat suurelta osin lukijoidensa, katsojiensa ja kuuntelijoidensa intressien sekä heidän kysyntänsä ja ostovoimansa ohjaamia" (emt., 119). Mielenkiintoista kyllä, Hjarvardille median lisääntyvä kaupallistuminen ei ole merkki median itsenäistymisen vähenemisestä tai "medialogiikan" merkityksen laskusta. Hän väittää että toimittajien sisäistämä ammatillisuuden ideaali varmistaa sen, että mediat lisäävät tai ainakin säilyttävät autonomiansa muihin instituutioihin nähden. Niinpä "mediat ovat vuorovaikutuksessa muiden sosiaalisten instituutioiden kanssa, mutta sellaisesta asemasta käsin joka on autonomisempi kuin mitä pelkkä markkinaorientaatio muutoin määräisi" (emt.).

Hjarvardin $(2008,120)$ väite, jonka mukaan median lisääntyvä markkinoituminen kulkee käsi kädessä lisääntyvän median autonomisoitumisen kanssa, on vähintäänkin kiistanalainen. Hjarvard myöntää tämän toisaalla itsekin kirjoittaessaan, että "siinä määrin kuin muut kentät tai instituutiot vaikuttavat mediaan, emme voi aina olla varmoja että havaittavat mediavaikutukset ilmaisevat pelkästään alistumista median logiikalle. Toisinaan medioituminen kulkee käsi kädessä kaupallistumisen ja politisoitumisen kanssa. Sen onko medioituminen kaikkein määräävin voima, voi määritellä vain erityisissä analyyseissä" (emt., 126; vastaavia ad hoc -tyyppisiä rajauksia tekee myös Altheide 2013, 225). Lisäksi Hjarvard $(2008,106)$ huomauttaa, että "mediat ovat yhtäältä yhteiskunnan ja kulttuurin kudosta ja toisaalta itsenäinen instituutio, joka sijaitsee muiden kulttuuristen ja yhteiskunnallisten instituutioiden välillä ja joka koordinoi niiden keskinäistä vuorovaikutusta". Kuitenkaan nämä monimutkaisuudet ja ristiriidat eivät näytä horjuttavan hänen uskoaan yleiseen "yhteiskunnan medioitumiseen", joka viittaa "yhteisesti koetun, medialogiikan sääntelemän maailman rakentumiseen" (emt., 129). Hjarvardin mukaan historiallisista syistä oli ymmärrettävää, että klassisen sosiologian suurnimet (kuten Weber, Marx, Durkheim tai Simmel) sivuuttivat median tärkeyden, mutta yhtä loogista on, että nykypolven sosiologit tiedostavat median merkittävyyden: "Myöhäismodernin yhteiskunnan sosiologiselle tutkimuk- 
selle teoria median kulttuurisesta ja yhteiskunnallisesta tärkeydestä ei ole enää vain kiinnostava mahdollisuus vaan ehdoton välttämättömyys." (Emt., 133.)

Hjarvardin kuten myös Altheiden ja Snown, Schultzin, Schrottin sekä Strömbäckin ja Esserin väitteet "medialogiikan" hallitsevuudesta eivät ole vakuuttaneet kaikkia sellaisiakaan mediatutkijoita, jotka muuten allekirjoittavat teesin medioitumisesta. Krotz $(2009,26)$ pitää medialogiikan käsitettä "harhaanjohtavana", sillä hänen mukaansa ei ole olemassa mitään yhtenäistä, erityisistä medioista riippumatonta medialogiikkaa. Niinpä esimerkiksi television logiikka eroaa älypuhelinten logiikasta, ja toisaalta se minkälainen logiikka jollain teknologialla katsotaan olevan, on riippuvainen sosiaalisista ja kulttuurisista konteksteista. Lundby $(2009,116)$ on samaa mieltä ja huomauttaa että "medioitumista ei ole mahdollista ymmärtää medialogiikan avulla", sillä "digitaalisen median erityisyydet täytyy myös ottaa huomioon". Hepp (2009, 140) näkee, että ajatus medialogiikasta johtaa "lineaariseen näkemykseen". Sen sijaan mediaa ja sen kehitystä tulee ymmärtää "kompleksisempien lähestymistapojen" avulla - sellaisten, jotka eivät oleta "yhtä lineaarista medialogiikkaa" vaan jotka tekevät mahdolliseksi tutkia "huolellisesti ja yksityiskohtaisesti tiettyjen kulttuuristen kenttien medioitumista" (emt.). Myös Couldry on kritisoinut medialogiikan ideaa vastaavasti. Hän näkee ongelmana sen, että median ajatellaan alistavan muun yhteiskunnan suhteellisen vaivattomasti valtaansa ja että tämä valta "operoi saumattomasti sosiaalisen tilan eri osissa ja niiden yli" (Couldry 2012, 136). Tämä näkemys on ongelmallinen senkin puolesta, että se asettuu vastoin "monia vaikutusvaltaisia sosiologisia lähestymistapoja", jotka eivät näe yhteiskuntaa yhtenäisenä vaan "eriytyneenä useisiin keskenään kilpaileviin kenttiin", ja että tämä eriytyminen tekee mahdottomaksi jonkin yksittäisen logiikan ensisijaisuuden (emt.).

\section{Heikko versio eli medioituminen "metaprosessina"}

Mikäli käsitys medialogiikasta ontuu näin pahasti, voidaanko väite medioitumisesta perustella toisin tavoin? Yleisesti ottaen yllä esitellyt kritiikit medialogiikkaa kohtaan ovat tyypillisesti yhdistyneet maltillisempiin muotoiluihin ja käsityksiin medioitumisesta, joissa korostetaan niitä eri konteksteja tai kenttiä joilla kyseinen prosessi on havaittavissa. Näitä käsityksiä voi kutsua medioitumisen teorian heikoksi muodoksi. Sen edustajat pyrkivät suhteellistamaan median vallan ja kyseenalaistamaan yhdenmukaisen medialogiikan olemassaolon, samalla kun he pohtivat medioitumista suhteessa muihin merkittävinä pidettyihin yhteiskunnallisiin ja kulttuurisiin kehityskulkuihin.

Heppin (2009, 143-144) käsitys medioitumisesta kytkeytyy ajatukseen, jonka mukaan eri medioilla on teknologisista ominaisuuksistaan juontuvaa "muokkaamisvoimaa" (Prägkraft). Toisin sanoen, eri mediateknologioilla on erityisiä ominaispiirteitä, jotka muovaavat sitä miten näitä medioita käytetään ja minkätyyppistä vuorovaikutusta ne tukevat. Näkemyksellä on ilmeisiä yhtymäkohtia ns. mediumteoriaan - erityisesti Marshall McLuhanin ja Joshua Meyrowitzin tuotantoon - jonka edusta- 
jat korostavat sitä, miten jokaisella mediateknologialla on erilaisia laajoja kulttuurisia vaikutuksia. Niinpä esimerkiksi Meyrowitzin $(1985,308)$ mukaan radion ja television merkittävin vaikutus on ollut siinä, että ne ovat "yhdistäneet aiemmin erilliset sosiaaliset miljööt", samalla kun ne ovat hämärtäneet yksityisen ja julkisen välisen eron. Vaikka Hepp $(2009,144)$ tunteekin ilmeistä vetoa tähän näkemykseen, hän kiirehtii lisäämään, että "eri medioiden erityispiirteet tuotetaan ihmisten toiminnassa" ja että "meidän täytyy tarkastella yksityiskohtaisesti sitä kuinka eri medioiden muovaamisvoimat konkretisoituvat [- - erilaisissa ulottuvuuksissa ja eri kulttuurisilla kentillä".

Heppin mukaan medioitumista voidaan tarkastella yhteyksissään kolmeen merkittävään yhteiskunnallis-kulttuuriseen kehityskulkuun. Nämä ovat yksilöllistyminen (yksilöiden identiteetin muodostuminen "refleksiivisesti" ilman perinteen, luokan, kansakunnan tai muiden kollektiivisten sidosten voimakasta tukea), deterritoriaalistuminen (kulttuurin irtoaminen aiemmista maantieteellisistä, kansallisista ja paikallisista sidoksistaan) ja mediavälitteisyyden kasvu (erityisesti ajateltaessa uuden digitaalisen median kykyä tuottaa reaaliaikaista läsnäoloa yli maantieteellisten etäisyyksien, mitä voi kutsua "kaukoläsnäoloksi" tai "viiveettömyyden kulttuuriksi", ks. Tomlinson 2007). Riippumatta siitä mitä vaikutuksia yhä enemmän "kaikkialla läsnä olevalla" medialla on eri konteksteissa (Hepp on tutkinut esimerkiksi uskonnollisia tapahtumia), nämä vaikutukset tulee yhdistää mainittuihin kolmeen sosiaaliseen, tilalliseen ja ajalliseen muutokseen, joiden toteutumiseen media siis itsekin vaikuttaa (Hepp 2009, 146-154). Tältä pohjalta Hepp toteaa, että emme voi tehdä mitään "yleisiä olettamuksia" vaan pelkästään puhua "mediaan kytkeytyvistä muutoksista jotka risteävät eri konteksteissa" (emt., 154). Heppin (2009, 146) medioitumisanalyysin kannalta kokoava teoreettinen huomio on se, että kansallisvaltiollinen, "territoriaalisesti ymmärretty joukkoviestintätila", ei ole enää pätevä viitekehys mediatutkimukselle. Sen sijaan hänen mukaansa mediakulttuurit ovat nykyisin laajentuneet globaaleiksi ja deterritorialisoituneet mutkikkailla tavoilla. Tämä väite on yhdenmukainen Ulrich Beckin (2007) "metodologisen nationalismin" kritiikin kanssa ja se myös toistaa kulttuurisen globalisaatioteorian perusväittämät (ks. Ampuja 2012, 255-338).

Krotz $(2007 ; 2009)$ on hahmotellut medioitumista vastaavin tavoin. Hän on nimennyt medioitumisen yhdeksi nykyajan metaprosessiksi globalisaation, yksilöllistymisen ja kaupallistumisen ohella. Nämä ovat prosesseja, jotka "vaikuttavat demokratiaan, yhteiskuntaan, kulttuuriin, politiikkaan ja muihin elämänehtoihin pitkällä aikavälillä" (Krotz 2007, 257). Medioituminen ei ole lähtökohtaisesti sen tärkeämpi kuin muut metaprosessit, joilla kaikilla on oma logiikkansa (emt., 259). Se kuvastaa kuitenkin mediaan liittyvien muutosten korostunutta merkitystä sekä mediaympäristön jatkuvaa monimuotoistumista: "medioituminen muuttaa viestintää tarjoamalla uusia viestimisen mahdollisuuksia" (emt., 259), samalla kun "mediasta on aikaa myöten tullut yhä tärkeämpi arkielämän sosiaalisessa rakentumisessa" (Krotz 2009, 24). Couldry $(2012,137)$ hyväksyy Krotzin näkemykset ja tähdentää, että vaikka media on "elimellinen osa kaikkia yhteiskunnallisia prosesseja", medioituminen ei viittaa "mihinkään yksittäiseen logiikkaan" ja siksi sen ilmenemismuodot ovat aina sidoksissa erityisiin sosiaalisiin kenttiin, joiden omat erityispiirteet täytyy myös tunnistaa. 
Medioitumisteorian heikon muodon eri edustajat jakavat monia yhteisiä näkemyksiä. Kaikille heille medioituminen on käsite, joka ilmaisee historiallista muutosta, jonka seurauksena media läpäisee yhä voimakkaammin kaikki sosiaalisen ja kulttuurisen elämän sfäärit. He hahmottavat medioitumisen kaikenkattavana kehityksenä, joka on kuitenkin vain yksi metaprosessi muiden joukossa. Heikon medioitumisteorian edustajat tuntevat ilmeistä vetoa viestintäteknologista kulttuurimuutosta korostavaan mediumteoriaan, joskin varauksellisesti. Lisäksi he kaikki korostavat, että yhteiskunnallis-kulttuurinen muutos on aina kompleksista ja monikausaalista, toisin sanoen se ilmentää kehityskulkuja joilla on omia, toisiinsa palautumattomia logiikoita. Tässä mielessä on silmiinpistävää, kuinka johdonmukaisesti yllä mainitut heikon teorian kannattajat nojautuvat Bourdieun teoreettisiin näkemyksiin kentistä, pääomista ja kilpailusta, joiden pohjalta he hahmottavat median "metapääomana", jota voi käyttää resurssina eri sosiaalisilla ja kulttuurisilla kentillä käytävässä valtakamppailussa (Couldry 2012, 139143; Hepp 2009, 149; Krotz 2009, 33-35).

\section{Medioitumistulkintojen vertailua}

Nopeasti arvioiden medioitumisteorian heikko versio näyttää elinvoimaisemmalta kuin sen vahva vastinparinsa, sen edustajat kun näyttävät välttäneen vahvan version ongelmallisella tavalla mediakeskeiset väittämät. Toisaalta myös heikko versio on altis vastaväitteille, joita käymme läpi seuraavaksi eri puolilta. Näiden kritiikkien yhtenä motiivina on se, että tähän mennessä medioitumisesta ovat keskustelleet pääasiassa käsitteen kannattajat, ja näin ollen sitä ei ole koeteltu riittävän perustavanlaatuisesti.

Ensinnäkin, miten medioituminen pitäisi ymmärtää historiallisesti? Missä tämän prosessin juuret ovat ja milloin siitä on tullut niin merkittävä, että sen voi sanoa muodostuneen omaksi "metaprosessikseen"? Näissä kysymyksissä törmäämme hyvin vaihteleviin näkemyksiin. Yhden niistä on tarjonnut brittisosiologi John B. Thompson (1995), jonka analyysejä mediasta ja modernisaatiosta on usein toistettu nykyisissä mediotumiskeskusteluissa. Thompson kirjoittaa:

Kirjapainoon ja myöhemmin informaation sähköiseen koodaamiseen perustuvien lukuisten teknologisten innovaatioiden ansiosta symbolisia muotoja voitiin tuottaa, jäljentää ja kierrättää ennennäkemättömässä mitassa. Viestinnän ja vuorovaikutuksen muodot alkoivat muuttua perusteellisesti ja peruuttamattomasti. Näillä muutoksilla, joita voimme löyhästi kutsua "kulttuurin medioitumiseksi" [mediazation] oli ilmeinen institutionaalinen pohjansa - nimittäin sellaisten mediaorganisaatioiden kehitys, jotka ilmaantuivat ensimmäisen kerran $1400-l u v u n$ jälkipuoliskolla ja jotka ovat aina siitä lähtien laajentaneet toimintaansa. (Thompson 1995, 45)

Krotz laajentaa aikaperspektiiviä entisestään. Hänelle (2009, 29) medioituminen on "pitkäjänteinen prosessi", sillä se viittaa "viestintään ihmisten sosiaalisen ja kulttuurisen maailman rakentamisen peruskäytäntönä". Medioituminen ulottuu näin ajallisesti 
kauas historiaan, joskin siihen liittyy myös "eriytymisprosessi", jossa "yhä useampi media kehittyy ja institutionalisoituu". Samalla tavoin Bruhn Jensen katsoo $(2013,214)$, että medioituminen "voidaan käsittää yhteiskunnallisen rakenteistumisen konstitutiivisena osana ja välttämättömänä edellytyksenä", joka on toteutunut "kautta koko inhimillisen viestinnän ja mediateknologioiden historian" ja joka kattaa myös "kasvokkain tapahtuvan viestinnän suullisissa kulttuureissa". Toisessa ajallisessa ääripäässä Hjarvard $(2008,108)$ edustaa niitä, jotka "käyttävät käsitettä kuvaamaan median vaikutusta muihin alueisiin kuten politiikkaan, kulutuskulttuuriin tai tieteeseen". Niinpä hänelle (emt., 113) "medioituminen ei ole universaali prosessi, joka luonnehtii kaikkia yhteiskuntia. Kyse on ensi sijassa kehityskulusta, joka on kiihtynyt erityisesti 1900luvun loppuvuosina moderneissa, hyvin teollistuneissa ja pääosin läntisissä yhteiskunnissa."

Couldry $(2012,137)$ on reagoinut ymmärrettävällä joskin intellektuaalisesti varsin epätyydyttävällä tavalla näiden toisistaan tavattomasti poikkeavien näkemysten tuottamiin ongelmiin: hän ei pidä kysymystä medioitumisen historiallisesta kehityksestä kovinkaan tärkeänä ja haluaa siksi "asettaa syrjään keskustelun siitä, voidaanko medioituminen jäljittää aina keskiajalle tai jo kauemmaksi, vai onko se parasta ymmärtää nimenomaan modernina ilmiönä". Kuitenkin Couldryn näkemyksen mukaan "medioitumisen käsitteen avulla tunnustamme samalla sen, että media on kaikkien sosiaalisten prosessien redusoimaton ulottuvuus" (emt.). Tämä tietenkin herättää hänen edellä sivuuttamansa kysymyksen siitä, mistä yhteiskunnista medioitumisen yhteydessä oikein on kyse. Couldryn vastaus kysymykseen historiallisesta paikantamisesta (jota hän ei siis halunnut asettaa) näyttäisi kuuluvan, että medioituminen on ollut osa kaikkia historian yhteiskuntia.

Toiseksi, kiistassa medioitumisen historiallisesta paikantamisesta on pohjimmiltaan kyse siitä, mitä medialla medioitumisdiskurssissa oikein tarkoitetaan. Näyttäisi siltä, että nykykäytössä media toimii eräänlaisena metakäsitteenä, jossa tarkemmin ottaen on kyse käsitteellisestä siirtymästä: sen sijaan, että puhuttaisiin viestintävälineistä ja niiden käyttöä (samoin kuin itse tätä käsitteellistä siirtymää) jäsentävistä yhteiskunnallisista ja viestinnällisistä suhteista, puhutaan "mediasta". Näin "media" nostaa uudella nimellä uuteen arvoon sen jo kritisoidun ja pitkälti hylätyn käsityksen, jossa "viestintää" hahmotetaan instrumentalistisesti tiettynä siirtojärjestelmänä. Itse asiassa viestintää ei voi kuitenkaan olla ilman vastaavaa mediaa, jossa on kyse sen materiaalisesta tai sosiaalisesta muodosta, aivan yhtä vähän kuin voi olla yhteiskuntaa tai kulttuuria ilman viestintää. Näin media osoittautuu historiallisessa mielessä aivan yhtä kattavaksi käsitteeksi kuin viestintä. Paitsi koko joukon informaation, merkitysten tai koodien siirtoon erikoistuneita moderneja teknologioita hyödyntäviä käytäntöjä ja instituutioita se voi pitää sisällään myös sellaisia sangen yleisiä asioita kuin kieli, kirjoitustaito tai raha. Aivan kuten välineellinen tai tekninen - samoin kuin hermeneuttinen - tapa ymmärtää viestintä, myös nykyinen hallitseva tapa puhua mediasta ja medioitumisesta yleensä hämärtää sen, mistä niiden pitäisi auttaa puhumaan selkeämmin: sosiaalisten käytäntöjen ja niiden keskinäisten artikulaatioiden historiallisissa konjunktuureissa saamista erilaisista institutionaalisista muodoista ja niistä käytävistä kamppailuista. 
Kolmanneksi, miten medioitumisen ja muiden metaprosessien (yksilöllistyminen, globalisaatio, kaupallistuminen) välinen suhde pitäisi ymmärtää? Krotz $(2007,259)$ kirjoittaa, että "näiden neljän metaprosessin väliset suhteet ovat monimutkaiset" ja että "kullakin metaprosessilla on oma kehityslogiikkansa, joskin kapitalistisessa maailmassa kaikki tällaiset metaprosessit ovat riippuvaisia taloudellisesta ulottuvuudesta" siten, että "kaupallistuminen on perusprosessi, joka stimuloi kaikkea toimintaa". Nämä näkemykset jäävät sangen epämääräisiksi ja osin ristiriitaisiksi, eivätkä medioitumisteorian puolestapuhujat ole havaintojemme mukaan pohtineet tätä problematiikkaa muissakaan yhteyksissä sen tarkemmin. Näyttää kuitenkin ilmeiseltä, että he yleensä pyrkivät yhteiskunnallisen ja kulttuurisen muutoksen "monikausaaliseen" selittämiseen välttääkseen syytökset reduktionismista. Jää kuitenkin epäselväksi, kuinka paljon analyyttistä voimaa tai selityskykyä medioitumisen käsitteellä tässä metaprosessien kimpussa loppujen lopuksi on. Miten esimerkiksi tulisi ymmärtää yhtä aikaa vaikuttavien kaupallistumisen ja medioitumisen metaprosessien väliset suhteet? Ovatko metaprosessit vain "asioita, jotka kieppuvat toistensa ympärillä", kuten Billig $(2013,122)$ sapekkaasti muotoilee?

Medioituminen on hohdokas käsite, mutta sen suhde muihin metaprosesseihin ja samalla sen oma teoreettinen asema jää hämäräksi - aivan kuten usein tapahtuu puhuttaessa muistakin metaprosesseista. Haasteena on, että "jokaisen teorian, jolla on kiinnostavaa sanottavaa yhteiskunnan rakenteesta ja yhteiskunnallisesta muutoksesta" täytyy "identifioida keskeiset käsitteet, joiden avulla se voi 'poimia esiin' monimutkaisessa kokonaisuudessa vaikuttavia avainmekanismeja ja -voimia" (McLennan 1996, 66-67). Mikäli keskeiset teoreettiset käsitteet ovat medioitumisteorian tavoin löyhässä suhteessa toisiinsa, saattaa helposti käydä niin, että teoreettisesti koherentin analyysin tai selityksen sijaan tuloksena on vain yhteiskunnallisen ja kulttuurisen muutoksen löyhää kuvailua.

Neljänneksi, medioitumisteorian heikossa versiossa on paljon horjuntaa sen suhteen, minkälaista selitysarvoa medioitumisella katsotaan olevan. Mitä "metaprosessi" analyyttisessä katsannossa itse asiassa tarkoittaa? Krotz $(2007,257)$ kirjoittaa, että metaprosessit ovat "konstruktioita, jotka kuvaavat ja selittävät teoreettisesti käynnissä olevan muutoksen tiettyjä taloudellisia, yhteiskunnallisia ja kulttuurisia ulottuvuuksia ja tasoja". Hepp (2009, 140) pitää medioitumista väljemmin "kehyksenä tutkia median ja kulttuurisen muutoksen välisiä suhteita".

Ongelmana on, että mikäli medioitumisen on todella tarkoitus "selittää" Krotzin sanoin "käynnissä olevan muutoksen tiettyjä taloudellisia, yhteiskunnallisia ja kulttuurisia ulottuvuuksia ja tasoja", kyse ei voi olla pelkästä kuvailevasta käsitteestä, sillä selittävän käsitteen tulisi viitata johonkin selkeästi analysoituun vaikutussuhteeseen. Krotz ja Hepp kuitenkin katsovat, että medioituminen on itse niin vahvasti riippuvainen muista yhteiskunnallisista ja kulttuurisista voimista ja konteksteista, että he varovat tuollaisen vaikutusyhteyden esittämistä. Medioitumisteorian heikon version tapa hahmottaa keskeinen käsitteensä muistuttaa tässä suhteessa kiinnostavasti globalisaation käsitteestä käytyä akateemista keskustelua (ks. Rosenberg 2005, 11-15). Kyse on siitä, että pyrkimyksiin kohottaa käsitteen teoreettista ja analyyttistä statusta liite- 
tään lopulta niin runsaasti asiaa mutkistavia lisäehtoja, että on epäselvää "kyetäänkö selkeää argumenttia ylipäätään esittämään" (emt., 14). Vetäessään yhteen omaa kantaansa Hepp (2009, 154) kirjoittaakin oireellisesti, että "parhaassakin tapauksessa medioituminen ei ole muuta kuin käsite, jolla voidaan linkittää yhteen [- - ] erilaisia erityistutkimuksia yleisemmäksi analyysiksi median vaikutusvoimasta kulttuurisessa muutoksessa". Niinpä kaikista "medioitumisteorian" (emt., 140) muodostamiseen kootuista voimavaroista huolimatta näyttääkin siltä, ettei tuollaista teoriaa ole itse asiassa kyetty muotoilemaan. Toisin sanoen medioitumisessa on lopulta kyse kuvailevasta käsitteestä, joka viittaa "prosessiin, jossa tekninen viestintämedia leviää yhä enemmän eri yhteiskunnallisissa ja kulttuurisissa piireissä" (emt., 141). Sinänsä tätä prosessia voidaan lähestyä useista erilaisista teoreettisista näkökulmista, joilla ei ole välttämättä mitään tekemistä sen ajatuksen kanssa, että media olisi itsenäinen voima (teknologiana tai jollain muulla tavalla), joka aiheuttaa ja selittää tuon leviämisprosessin. Myös Krotz (kuten jossain määrin myös Hepp) kytkee medioitumislähestymistapansa muihin olemassa oleviin teorioihin (joita ovat esittäneet mm. Jürgen Habermas, Michel Foucault, Pierre Bourdieu ja Norbert Elias) siinä määrin, että se uhkaa menettää väitetyn itsenäisyytensä erityisenä teoreettisena lähestymistapana mediatutkimuksessa.

\section{"Medioitumisen" merkitys tutkimusalan identiteetille}

Runsaasta keskustelusta huolimatta medioitumisen analyyttinen merkitys on jäänyt perin epäselväksi. Tämä ei ole estänyt medioitumisteorian vahvan ja heikon version edustajia saavuttamasta merkittävää menestystä, mikä näkyy lisääntyvinä julkaisuina ja konferensseina. Näin siitäkin huolimatta, että näiden monesti yhdessä esiintyvien kahden version edustajien välillä on pohjimmiltaan merkittäviä teoreettisia erimielisyyksiä, kiistäväthän heikon version edustajat itse asiassa koko vahvan version perustavan lähtökohdan eli väitteet "medialogiikasta".

Molemmille versioille yhteisellä medioitumisdiskurssilla lienee kuitenkin ainakin lähivuosina edessään valoisa tulevaisuus. Tämä liittyy siihen strategiseen merkitykseen, jota termiin on liitetty koko mediatutkimuksen tulevaisuuden kannalta. Medioitumisen puolestapuhujille on luonteenomaista väittää, että media on yhteiskunnallisen ja kulttuurisen muutoksen ytimessä. Tämä ajatus on omiaan nostamaan mediatutkimuksen asemaa yhteiskuntatieteiden ja -teorian kentällä. Medioitumisdiskurssilla on tässä kunnianhimoisuudessaan vähän edeltäjiä media- ja viestintätutkimuksen piirissä. Laajojen, eri tutkimusalat ylittävien tai yhdistävien yhteiskuntateoreettisten peruskäsitteiden tuottajinahan ovat yleensä kunnostautuneet sosiologian, antropologian tai politiikan tutkimuksen edustajat media- ja viestintätutkijoiden sijaan.

Historiallisesti mediatutkimus on ollut siinä määrin likeisessä yhteydessä muihin oppialoihin (kuten sosiologiaan, politiikan tutkimukseen, taloustieteeseen, kirjallisuuteen, filosofiaan, sosiaalipsykologiaan ja antropologiaan), että sillä ei ole ollut "mitään selkeästi osoitettavia tieteenalarajoja" ja siksi se on usein hahmotettu väljemmin "tutkimuskenttänä" (Koivisto \& Thomas 2010, 28). Pyrkimyksiä tehdä tutkimuskentästä 
itsenäinen tieteenala, jolla on muista yhteiskunta- tai inmistieteistä eroava oma tutkimuskohteensa, metodologiansa ja lähestymistapansa ei ole kuitenkaan puuttunut. Näitä pyrkimyksiä ei ole ollut helppo toteuttaa tutkimuskentällä esiintyneiden lähestymistapojen ja näkökulmien empiirisestä moninaisuudesta johtuen. Viime vuosikymmenet ovat merkinneet akateemisen mediatutkimuksen jyrkkää kasvua (emt., 13-25), mutta se ei ole poistanut huolta tuon tutkimuksen selkeästä tieteenalaidentiteetistä. Niinpä "'medioitumisen' ilmaantuminen yhteen kokoavana käsitteenä viime vuosikymmenen loppupuolella" (Couldry \& Hepp 2013, 192) pitää sisällään lupauksen mediatutkimuksen uudenlaisesta koherenssista ja "saattaa auttaa meitä kehittäessämme kentästä tieteenalaa" (Hjarvard 2012, 33). Kuten Bruhn Jensen $(2013,13)$ toteaa, "on kiinnostavaa, miten monet eri teoreettisen taustan ja kiinnostuksen kohteen omaavat tutkijat ovat viime vuosikymmenen aikana yhdessä omaksuneet medioitumisen käsitteen".

Medioitumisen käsite näyttää tarjoavan mahdollisuuden keskustella median muutoksen eri puolista sellaisella uudella kokonaisvaltaisella tavalla, joka voisi yhdistää alan eri keskusteluja. Krotzin $(2007,256)$ mukaan "maailmanlaajuinen akateeminen viestintätutkimus tarvitsee yhteistä käsitteellistä kehystä, joka auttaisi sen tuottaman tiedon yhdentämisessä ja levittämisessä". Hänelle "medioituminen" on tuon kehyksen keskiössä. Samoin myös Couldrylle ja Heppille $(2013,191)$ "kauttaaltaan institutionalisoitunut viestintätutkimuksen kenttä tarvitsee kipeästi yhteisiä termejä, jotka voivat orientoida monilta eri maantieteellis-kielellisiltä alueilta ja eri maista tulevia tutkijoita kohti yhteisiä ongelmia ja tutkimusalueita”. Livingstone $(2009,3)$ esittää edellistä laajentumishaluisemman ajatuksen pohtiessaan käsitteiden mediavälitteisyys (mediation) ja medioituminen (mediatization) merkitystä tieteenalakehitykselle: "meillä näyttää media- ja viestintätutkimuksessa olevan halua ei vain puolustaa omaa aluettamme vaan myös laajentaa sitä muiden tieteenalojen perinteisesti hallussaan pitämille alueille".

Vaikka medioitumisen teoreettiset seuraukset ja sen mahdollisuudet kehittyä vahvaksi paradigmaksi tai tutkimusohjelmaksi "ovat epävarmoja", tämä ei tarkoita sitä, että kyseinen "arkijärkinen nyky-yhteiskunnan ja kulttuurin luonnehdinta" (Bruhn-Jensen 2013, 218) olisi epäkiinnostava tai merkityksetön. Ensinnäkin tutkimusrahoitusta koskevissa kamppailuissa medioituminen ja siihen liittyvät epäpolitisoivat, teknologia- ja mediakeskeiset äänenpainot voivat osoittautua erinomaisen hyödyllisiksi (vanhastaan tuttujen "informaatioyhteiskunnan", "tietoyhteiskunnan" ja "verkostoyhteiskunnan" tapaan). Hintana tosin on huomion siirtäminen pois yhteiskunnallisista suhteista ja niistä käytävistä kamppailuista sekä siitä, miten edelliset kytkeytyvät teknologian kehitykseen, sillä näiden asioiden tutkiminen edellyttäisi laajempaa ja vähemmän oman tieteenalapyrkimyksen hallitsemaa teoreettista sanastoa. Toiseksi, medioitumiseen liitetty tutkimus on parhaimmillaan tuottanut tärkeitä huomioita siitä, miten eri instituutiot ja yhteiskunnalliset ryhmät pitävät mediaa yhä tärkeämpänä oman toimintansa kannalta. Esimerkiksi poliitikot ja heidän avustajansa käyttävät aiempaa enemmän aikaa sen pohtimiseen, miten poliitikot ja heidän politiikkansa esitetään mediassa ja miten he voisivat kehittää mediastrategioitaan. Kuitenkin vakiintuneet poliittiset instituutiot ja organisaatiot hallitsevat poliittista prosessia yhä monin tavoin, vaikka niiden on sovitettava toimintaansa median päiväjärjestykseen, muotoihin ja ilmaisutapoihin. Poliit- 
tisten organisaatioiden kyky ymmärtää median toimintaa voi lisätä niiden omaa valtaa. Yhtä kaikki, poliittisia valtataisteluja eivät määritä vain poliittiset instituutiot ja media vaan myös muut yhteiskunnalliset suhteet, instituutiot ja diskurssit.

Teoria medialogiikasta tai medioitumisen innokas esittäminen yhteiskuntatieteiden keskeisenä käsitteenä osoittautuu aivan liian yksinkertaiseksi ja yksioikoiseksi näkökulmaksi. Kuten Billig $(2013,114)$ huomauttaa, mediatutkijat ovat panostaneet paljon medioitumiseen tietynlaisen "lähestymistavan brändinimenä" ilman, että he olisivat pohtineet paljonkaan sitä, mitä tämän innostuksen keskellä ja tähän käsitteen tukeutuen "jää tekemättä". Sekä vahvan että heikon medioitumisteorian viimekätinen mediakeskeisyys estää molempien versioiden puolestapuhujia hahmottamasta teoreettisesti vakuuttavasti media roolia suhteessa muihin keskeisiin yhteiskunnallisiin, taloudellisiin ja poliittisiin suhteisiin ja instituutioihin. Näiden instituutioiden monimutkaiset vuorovaikutussuhteet ja artikulaatiot eivät mitenkään vääjäämättömästi näytä todistavan median yhä lisääntyvästä vallasta nykyisessä konjunktuurissa.

Tämä on Nordicom Review'ssä julkaistavan artikkelin suomennettu ja hieman muokattu versio.

\section{Kirjallisuus}

Altheide, David \& Snow, Robert (1979). Media Logic. Beverly Hills, CA: Sage.

Altheide, David (2013). Media Logic, Social Control, and Fear. Communication Theory 23: 3, 223-238.

Ampuja, Marko (2012). Theorizing Globalization. A Critique of the Mediatization of Social Theory. Leiden/ Boston: Brill.

Asp, Kent (1986). Mäktiga Massmedier: Studier i Politisk Opinionsbildning. Stockholm: Akademilitteratur.

Beck, Ulrich (2007). The Cosmopolitan Condition. Why Methodological Nationalism Fails. Theory, Culture Q Society 24: 7-8, 286-290.

Billig, Michael (2013). Learn to Write Badly. How to Succeed in the Social Sciences. Cambridge: Cambridge University Press.

Bruhn Jensen, Klaus (2013). Definitive and Sensitizing Conceptualizations of Mediatization. Communication Theory 23: 3, 203-222.

Couldry, Nick (2008). Mediatization or Mediation? New Media and Society 10: 3, 373-391.

Couldry, Nick (2012). Media, Society, World. Social Theory and Digital Media Practice. Cambridge: Polity Press.

Couldry, Nick \& Hepp, Andreas (2013). Conceptualizing Mediatizations: Contexts, Traditions, Arguments. Communication Theory 23: 3, 191-202.

Fornäs, Johan (1998). Kulttuuriteoria. Tampere: Vastapaino.

Hepp, Andreas (2009). Differentiation: Mediatization and Cultural Change. Teoksessa: Lundby, Knut (toim.). Mediatization. Concept, Changes, Consequences. New York: Peter Lang, 139-157.

Hepp, Andreas; Hjarvard, Stig \& Lundby, Knut (2010) Mediatization - Empirical Perspectives: An Introduction to a Special Issue. Communications 35: 3, 223-228.

Herkman, Juha (2001). Audiovisuaalinen mediakulttuuri. Tampere: Vastapaino.

Hjarvard, Stig (2008). The Mediatization of Society. A Theory of the Media as Agents of Social and Cultural Change. Nordicom Review 29: 2, 105-134.

Hjarvard, Stig (2012). Doing the Right Thing. Media and Communication Studies in a Mediatized World. Nordicom Review, Supplement 33: 1, 27-34. 
Kantola, Anu (2011). Modernin julkisuuden teoria ja käytännöt. Teoksessa: Kantola, Anu (toim.). Hetken hallitsijat. Helsinki: Gaudeamus, 17-41.

Koivisto, Juha \& Thomas, Peter (2010). Mapping Communication and Media Research: Conjunctures, Institutions, Challenges. Tampere: Tampere University Press.

Krotz, Friedrich (2007). The Meta-Process of 'Mediatization' as a Conceptual Frame. Global Media and Communication 3: 3, 256-260.

Krotz, Friedrich (2009). Mediatization: A Concept With Which to Grasp Media and Societal Change. Teoksessa: Lundby, Knut (toim.). Mediatization. Concept, Changes, Consequences. New York: Peter Lang, 139-157.

Kunelius, Risto; Noppari, Elina \& Reunanen, Esa (2009). Media vallan verkoissa. Tampereen yliopisto, tiedotusopin laitos, julkaisuja 112/2009.

Livingstone, Sonia (2009). On the Mediation of Everything. Journal of Communication 59: 1, 1-18.

Lundby, Knut (2009). Introduction: 'Mediatization' as Key. Teoksessa: Lundby, Knut (toim.). Mediatization. Concept, Changes, Consequences. New York: Peter Lang, 1-18.

Mazzoleni, Gianpietro \& Schultz, Winfried (1999). 'Mediatization' of Politics: A Challenge for Democracy? Political Communication 16: 3, 247-261.

McLennan, Gregory (1996). Post-Marxism and the 'Four Sins' of Modernist Theorizing. New Left Review I, 218, 53-74.

Meyrowitz, Joshua (1985). No Sense of Place. The Impact of Electronic Media on Social Behavior. New York: Oxford University Press.

Reunanen, Esa; Kunelius, Risto \& Noppari, Elina (2010). Mediatization in Context: Consensus Culture, Media and Decision Making in the 21st century, the Case of Finland. Communications 35: 3, 287-307.

Rosenberg, Justin (2005). Globalization Theory: A Post Mortem. International Politics 42: 1, 2-74.

Schrott, Andrea (2009). Dimensions: Catch-All Label or Technical Term. Teoksessa: Lundby, Knut (toim.) Mediatization. Concept, Changes, Consequences. New York: Peter Lang, 41-62.

Schulz, Winfried (2004). Reconstructing Mediatization as an Analytical Concept. European Journal of Communication 19: 1, 87-101.

Seppänen, Janne \& Väliverronen, Esa (2012). Mediayhteiskunta. Tampere: Vastapaino.

Silverstone, Roger (2005). The Sociology of Mediation and Communication. Teoksessa: Calhoun, Craig; Rojek, Chris \& Turner, Bryan S. (toim.). The SAGE Handbook of Sociology. London: Sage, 188-207.

Somerville, Margaret A. (1997). Euthanasia in the Media: Journalists' Values, Media Ethics and 'Public Square' Messages. Humane Health Care International 13: 1, 17-20.

Strömbäck, Jesper \& Esser, Frank (2009). Shaping Politics: Mediatization and Media Interventionism. Teoksessa: Lundby, Knut (toim.). Mediatization. Concept, Changes, Consequences. New York: Peter Lang, 205-224.

Strömbäck, Jesper \& Dimitrova, Daniela V. (2011). Mediatization and Media Interventionism: A Comparative Analysis of Sweden and the United States. The International Journal of Press/Politics 16: 1, 30-49.

Sumiala, Johanna (2011). Median rituaalit. Johdatus media-antropologiaan. Tampere: Vastapaino.

Thompson, John B. (1995). The Media and Modernity: A Social Theory of the Media. Cambridge: Polity Press.

Tomlinson, John (2007). The Culture of Speed: The Coming of Immediacy. London: Sage.

Väliverronen, Esa (2001). From Mediation to Mediatization: The New Politics of Communicating Science and Biotechnology. Teoksessa: Kivikuru, Ullamaija \& Savolainen, Tarja (toim.). The Politics of Public Issues. Department of Communication, University of Helsinki, 157-178.

Väliverronen, Esa (2002). Tarinoita Huomenesta - eli miten biotekniikan tulevaisuutta tuotetaan. Tiedotustutkimus 25: 1, 109-124.

Williams, Raymond (1983). Keywords: A Vocabulary of Culture and Society. (Revised Edition.) London: Fontana. 